\title{
Orofacial Clefts: A Clinical Community Study in a Developing Country
}

\author{
Pius Agbenorku, ${ }^{1}$ Thomas Diby, ${ }^{2}$ Margaret Agbenorku, ${ }^{3}$ Fritz Abude, \\ Randy Sefenu, ${ }^{4}$ Daniel Osei, ${ }^{4}$ Mary Kofitse, ${ }^{4}$ and Edem Maniwa ${ }^{4}$ \\ ${ }^{1}$ Reconstructive Plastic Surgery \& Burns Unit, Komfo Anokye Teaching Hospital, School of Medical Sciences, \\ Kwame Nkrumah University of Science and Technology, Kumasi, Ghana \\ ${ }^{2}$ Department of Anatomy, School of Medical Sciences, Kwame Nkrumah University of Science and Technology, Kumasi, Ghana \\ ${ }^{3}$ Health Education Unit, Global Evangelical Mission Hospital, Apromase-Ashanti, Ghana \\ ${ }^{4}$ Department of Surgery, South Tongu District Hospital, Sogakope, Ghana
}

Correspondence should be addressed to Pius Agbenorku; pimagben@yahoo.com

Received 17 September 2012; Accepted 9 October 2012

Academic Editors: C. Maldonado, H. Mizuno, and E. Raposio

Copyright (C) 2013 Pius Agbenorku et al. This is an open access article distributed under the Creative Commons Attribution License, which permits unrestricted use, distribution, and reproduction in any medium, provided the original work is properly cited.

Aim. The study aimed at finding the types of orofacial clefts, reasons for delay in the repair of the deformity and medium through which patients and/or their relatives heard about the outreach program. Methods. This study was from 2009 to 2011 at two different study sites. The team visited various media houses and health facilities at each study site to disseminate information concerning the cleft outreach program. Patients and/or their parents who visited the hospitals were interviewed using a questionnaire designed for the study to retrieve needed information for the study. Patients were then examined and booked for cleft repair by specialists in the team. Results. A total of 61 patients were recorded from both study sites, with ages ranging from 3/12 to 54 years old, with a mean age of $6.7 \pm 2.7(\mathrm{SD})$ years; while, male : female ratio was $1.05: 0.5$. Cleft lip only $(52.5 \%, n=32)$ was the highest type of orofacial cleft recorded in the study. In terms of occurrence, complete cleft ( $63.9 \%, n=39)$ was majority; while, position-wise, unilateral cleft right $(32.8 \%, n=20)$ was the highest. A significant $(P=0.017)$ association between males and unilateral right cleft lips was identified. Lack of finance $(47.5 \%, n=29)$ was the main reason for delaying in deformity repair. Also, information from physician $(41.0 \%, n=25)$ was the major medium for information dissemination. Conclusion. Unilateral cleft lip constitutes most of the orofacial clefts in this study, with lack of finance being the commonest reason why patients delay in the repair of their deformity.

\section{Introduction}

Most Cleft Lip (CL) and Palate (CP) studies are based on hospital or birth registry statistics which may not reflect the true incidence of the disease. Even though community-based surveys may reflect close to true incidence, they are difficult to conduct. It requires a large knowledgeable work force and is time consuming and expensive. In developing countries such as Ghana, untreated CLs and CPs are found with increasing frequency, and patients often present to the surgeon far past the optimal time for closure of the cleft deformities.

Orofacial clefts are common congenital malformations whose etiology is complex and likely to have both genetic and environmental etiology [1-4]. Although numerous techniques and protocols are employed in the repair of this congenital deformity, the surgical literature is consistent in recommending early repair, typically completing primary repair of the lip and palate by the age of two years [5]. A commonly accepted protocol in many surgical textbooks is repair of a cleft lip at 10 to 12 weeks of age, followed by primary palatoplasty at nine to 12 months of age, before development of speech $[1,5-7]$. It is well known that timely closure of palatal defect is associated with improved speech outcome $[6,8]$ and late closure of the palate has been clearly demonstrated to give a poor outcome $[7,9]$. In addition, delayed repair of the cleft can lead to impaired family and 
societal relationships with potential long-term psychological effects on the child [10,11].

In Ghana, the first community-based study on cleft was reported by Agbenorku et al. (2010), where they reported a cleft lip/cleft palate prevalence of 5.0 per 1000 people in the Wudoaba communities in the southeastern border of Ghana [12]. A retrospective review of cleft lip and palate operations carried out at the Komfo Anokye Teaching Hospital (KATH) in Kumasi, Ghana, reported that a total of 344 patients were operated on for cleft lip with or without palate $(\mathrm{CL}+/ \mathrm{P})$ during the 5-year period (2001-2005), that is, 69 operations per year [13]. Again in KATH, a four-years (2006-2009) review of clefts repaired cases by Agbenorku et al. (2011) reveals a higher incidence of congenital cleft abnormalities repaired during the period under review (i.e., 132 surgeries per year). Most prevalence reports on $\mathrm{CL}+/ \mathrm{P}$ had their data from hospitals, with relatively few studies done in communities [14].

The model of this study was different. Information about CL and CP were disseminated through radio stations announcements and Churches, hospitals, schools, and community centers by the education team of the outreach and volunteers in both areas of the study. Two hospitals were selected for the cleft repair surgery after the community educations. This study aimed at finding the types of orofacial clefts in the study areas, reasons for delay in the repair of the deformity, and the commonest information medium through which patients and/or their relatives heard about the outreach programs.

\section{Materials and Methods}

2.1. Study Settings. The Global Evangelical Mission Hospital (GEMH) located at Apromase, a village about $10 \mathrm{~km}$ southwest of Ejisu, the capital of the Ejisu-Juaben Municipal and also about $12 \mathrm{~km}$ southeast of Kumasi. The hospital has thirty-five beds and is well known in the region for its expertise in skin ulcer and orofacial cleft management. Patients from different facilities have been referred to GEMH from all over the country. A total of 2153 patients (out- and in-patients) visited the hospital in the year 2011 (Biostatistics Unit, 2011). The surgical department of the hospital has a standard surgical theater with a recovery ward.

The Sogakope study in the Volta Region was the second community-based study where cleft patients were also mostly grown-ups. After the dissemination of the cleft repair information through various media, patients came voluntarily to meet the team, where they were scheduled for surgery at the South Tongu District Hospital at Sogakope. Cases were reported from many towns and villages including Wudoaba (a very prone area for orofacial clefts).

2.2. Data Collection and Analysis. Ethical clearance for the study was approved by the Ethics Committee of the School of Medical Sciences, Kwame Nkrumah University of Science and Technology, Kumasi, Ghana. Demographic data for this prospective study from January 2009 till December 2011 were obtained from the patients or relatives of patients after giving their consent for the study. Information related to the surgical procedures were also recorded at the hospital prior to and after the surgery. Information collected included demographic features of the patients, medium through which the information about the team was heard, types of cleft lip/palate, number of cases seen, and surgeries performed. The data were then analyzed, and results, displayed in tables and graphs by using SPSS version 12.0 (SPSS, Inc, Chicago, IL).

\subsection{Patient Management}

2.3.1. Surgery Schedule. Technically, the surgery can be performed at any time after the child is born. In general, the rule of 10 was adopted. That is, the baby was operated on at about 10 weeks old, with body weight about $10 \mathrm{lb}$, that is, $4.5 \mathrm{~kg}$, and hemoglobin level of about $10.0 \mathrm{~g} / \mathrm{dL}$. The risks in general anesthesia are much reduced when these parameters are attained. For babies, cleft palates were customarily repaired at about 12 months of age.

2.3.2. Surgery for Unilateral Cleft Lip. The aim of the surgery is to repair the defect and realign the deranged muscle back to the normal anatomic position. The end result should be a lip with relatively normal look both aesthetically and dynamically. Millard's rotation-advancement repair method was the surgical technique used (Figures 1 and 2).

2.3.3. Surgery for Bilateral Cleft Lip. The preoperative formalities and the aim of the operation are the same as for unilateral cleft lip. The technique used was the straight-line procedure (Figure 3).

2.3.4. Surgery for Cleft Palate. The purpose of cleft palate operations is to produce anatomic closure and, eventually, normal speech, as well as to minimize maxillary growth retardation and dental alveolar deformity. It is important that the palatal defect be repaired before the child initially attempts to speak. The technique usually used was Langenbeck variant (Figure 4).

\section{Results}

3.1. Demographic Characteristics of Patients. A total of 61 patients were recorded from both study sites, with ages ranging from $3 / 12$ to 54 years old, with a mean age of $6.7 \pm 2.7$ (SD) years (Figure 5). In terms of sex, males outnumbered females in the ratio 1.0:0.48.

3.2. Types of Orofacial Clefts among Patients. Cleft lip and/or alveolus only $(52.5 \%, n=32)$ was the highest type of orofacial cleft recorded in the study, followed by cleft palate only $(29.5 \%, n=18)$ as shown in Table 1 .

3.3. Occurrence and Position of Orofacial Clefts among Patients. Orofacial clefts were categorized and taken in consideration as it occurs and positions on the face of patients. 


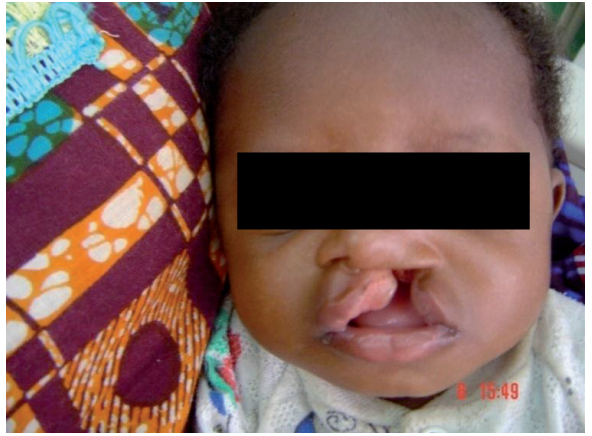

(a) PreSurgery

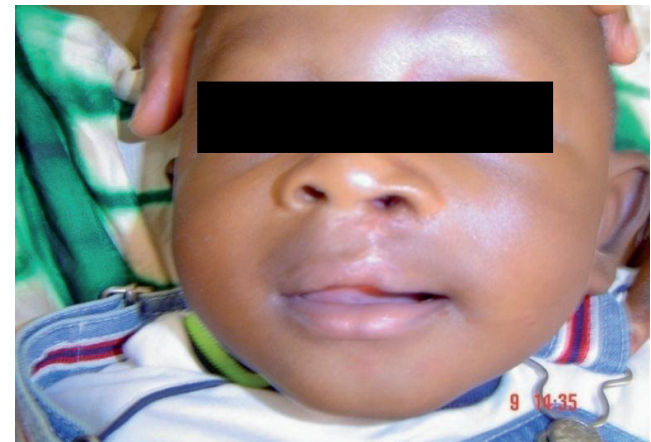

(b) PostSurgery

FIgURE 1: Unilateral Complete cleft lip in a 3 month-old child.

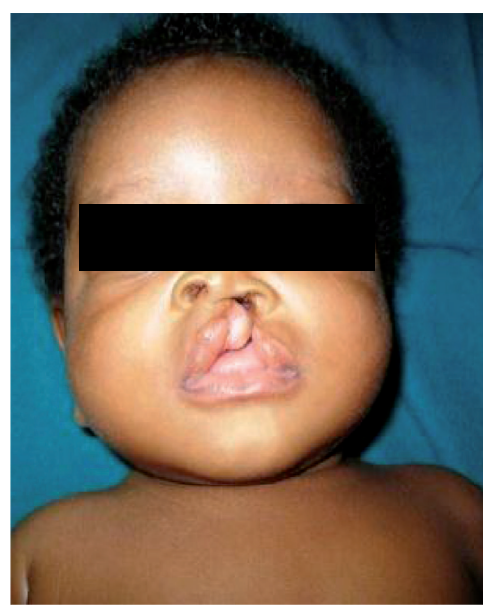

(a) PreSurgery

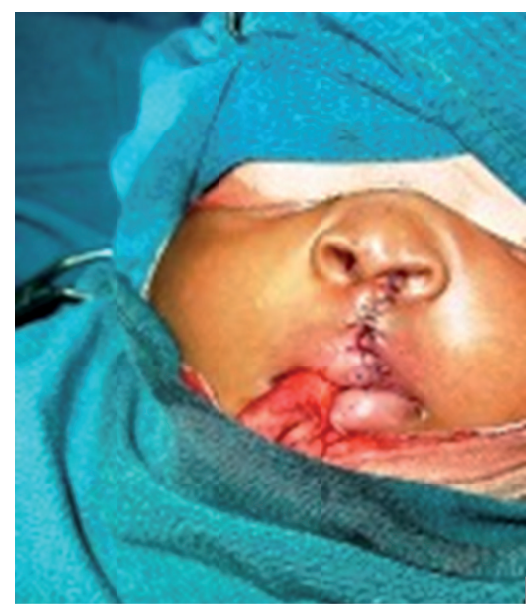

(b) PostSurgery

FIgURE 2: Unilateral Complete cleft lip in a 3 month-old child.

TABLE 1: Types of deformities among patients.

\begin{tabular}{lc}
\hline Category & Number (\%) \\
\hline Unilateral cleft lip \pm alveolus & $21(34.4)$ \\
Bilateral cleft lip \pm alveolus & $11(18.0)$ \\
Unilateral cleft lip and palate & $8(13.1)$ \\
Bilateral cleft lip and palate & $3(4.9)$ \\
Cleft hard and soft palate & $13(21.3)$ \\
Isolated cleft of soft palate & $5(8.3)$ \\
\hline Total & $61(100.0)$ \\
\hline
\end{tabular}

In terms of occurrence, complete cleft $(63.9 \%, n=39)$ outnumbered the incomplete $(36.1 \%, n=22)$ types; while, position-wise, unilateral cleft right $(32.8 \%, n=20)$ was the highest, as shown in Table 2.

3.4. Reasons for Delay in Presentation of Deformity. The most common reason for delay in deformity repair was lack of finance $(47.5 \%, n=29)$. Others included lack of awareness of treatment availability, superstition, fear of death from surgery, and long distance to health facilities (Table 3).
3.5. Information Dissemination Medium in Communities. Information from physicians/nurses $(41.0 \%, n=25)$ were the major medium through which patients and/or their parents heard about the cleft outreach program. Other recorded media included TV/radio (FM) stations. Friends/relatives, charity organizations such as churches and mosques were also important media (Figure 6).

3.6. Analysis of Data. Logical Regression analysis was used to determine possible significant association between patients' demographic features and cleft deformity in the study. A probability value $(P$-value) of less than 0.05 was considered to be statistically significant at $95 \%$ confidence interval.

Demographic features used were age and sex; characteristics of clefts used included type, occurrence, and position. The analysis of the results reveals a significant $(P=0.017)$ association between males and unilateral right cleft lips (Table 4).

\section{Discussion}

In developed countries, with the advancement of medical services and awareness among patients, it is rare to find adults 


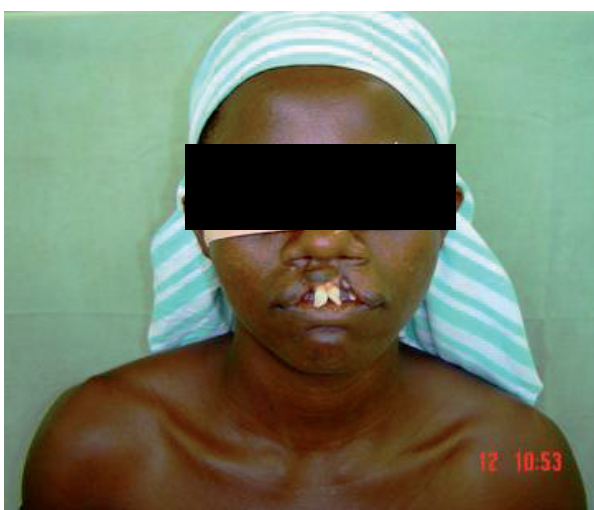

(a) Pre-surgery front view

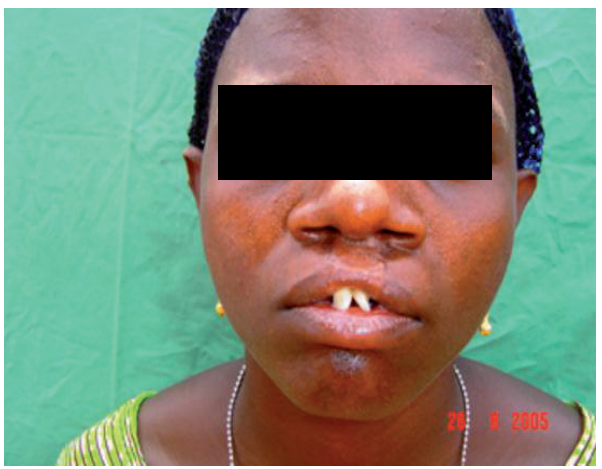

(c) Post-surgery front view

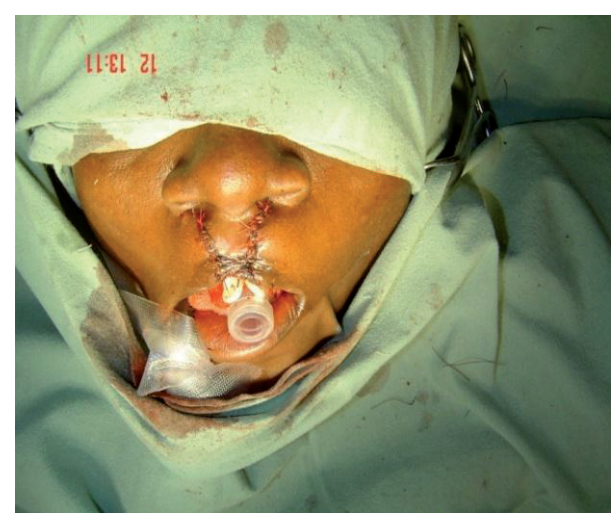

(b) Surgery: Straight-line repair procedure

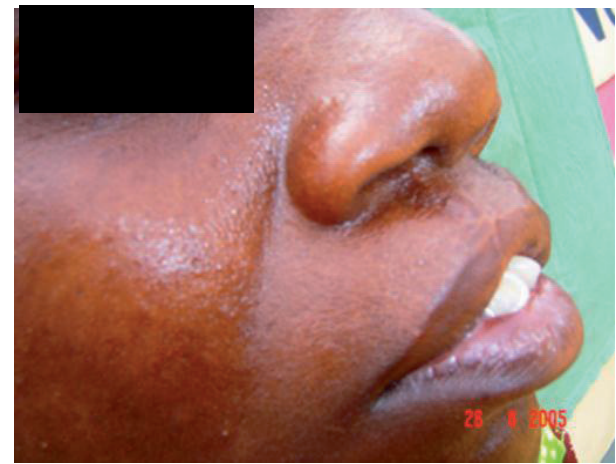

(d) Post-surgery right side view

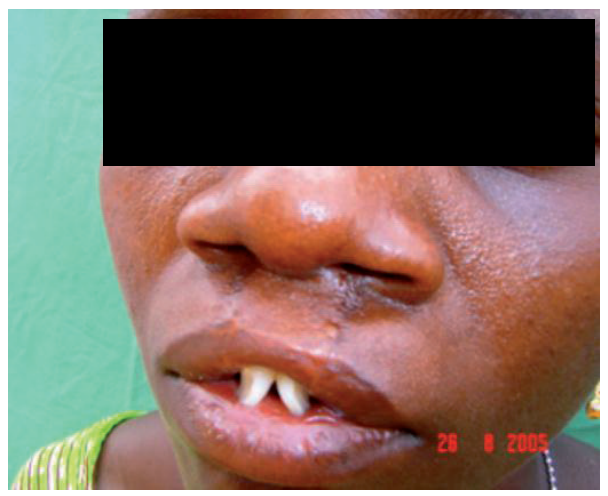

(e) Post-surgery left side view

FIgURE 3: Repaired bilateral cleft lip in a 26-year-old lady.

TABLE 2: Characteristics of orofacial clefts among the patients.

\begin{tabular}{lccccccc}
\hline \multirow{2}{*}{ Cleft } & \multirow{2}{*}{ Frequency $(n)$} & \multicolumn{2}{c}{ Occurence } & \multicolumn{3}{c}{ Postion } \\
& & Complete & Incomplete & Unilateral CP & Bilateral & Unilateral right & Unilateral left \\
\hline Cleft lip & 32 & 28 & 4 & - & 11 & 17 & 4 \\
Cleft palate & 18 & 0 & 18 & 18 & 0 & - & - \\
Cleft lip/palate & 11 & 11 & 0 & - & 3 & 3 \\
\hline
\end{tabular}

with unoperated CL and CP. However, the scenario is totally different in developing countries. The report of more CL in males and more CP in females from the African studies is consistent with the literature $[15,16]$. The overall report of $\mathrm{CL} / \mathrm{CP}$ being higher in males in the African studies is also consistent with the literature [15]. The wide range in the confidence intervals in most of the studies suggests that the precision is low, which may be a result of poor ascertainment of cases. The results of this study show a high number of males as compared to females. Furthermore, unilateral CL 


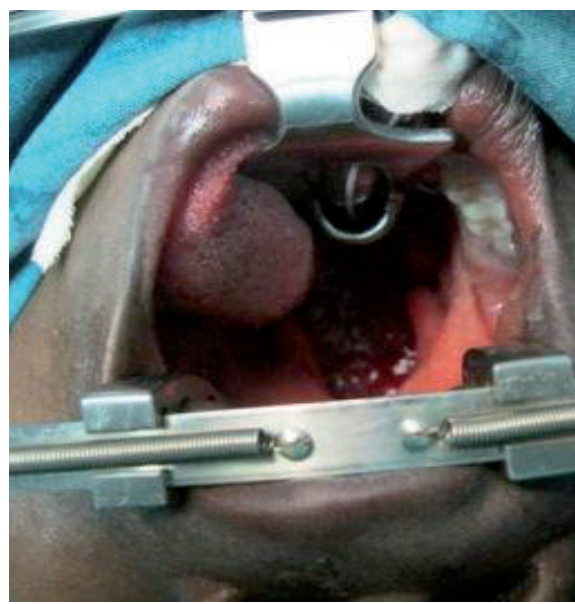

(a) PreSurgery

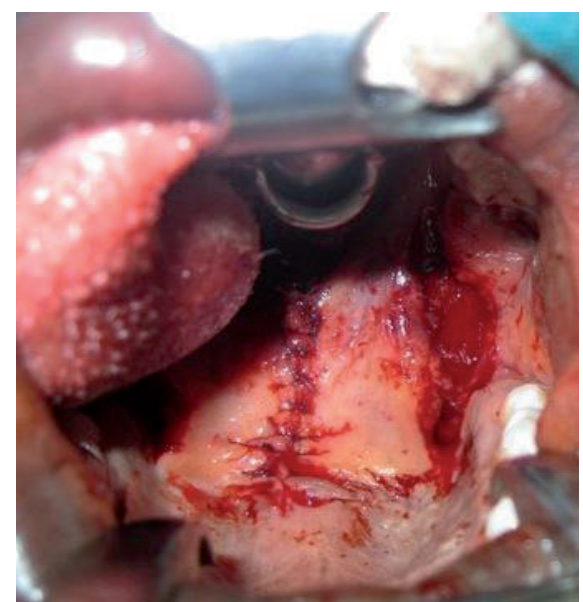

(b) PostSurgery

FIGURE 4: A 22-year-old cleft palate patient.

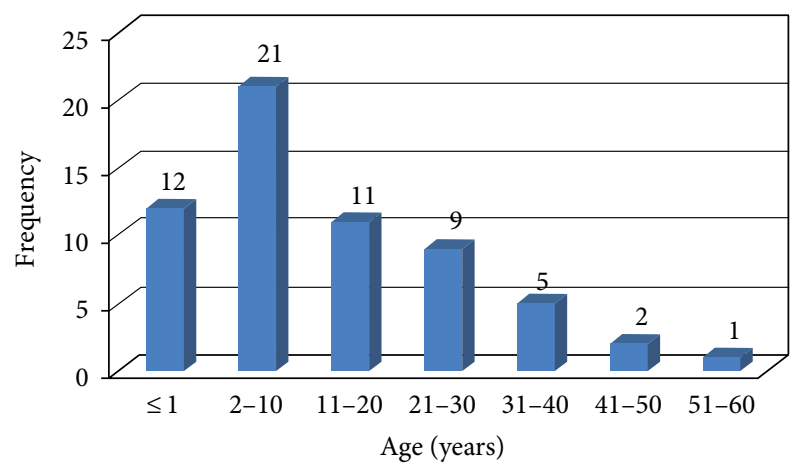

FIGURE 5: Age distribution of patients.

TABLE 3: Reasons for late presentation.

\begin{tabular}{lc}
\hline Reason & Number (\%) \\
\hline Lack of awareness of treatment availability & $12(19.7)$ \\
Lack of finance & $29(47.5)$ \\
Fear of death from surgery & $7(11.5)$ \\
Superstition & $9(14.8)$ \\
Distance to health facilities & $4(6.5)$ \\
\hline Total & $61(100.0)$ \\
\hline
\end{tabular}

was revealed to be the most prevalent type of orofacial cleft among the patients. To buttress the findings of the study, an analysis to determine the significant association between demographic features and orofacial cleft was performed. The regression analysis reveals that being a male is a risk factor for unilateral right $\mathrm{CL}(P=0.017)$; no other significant was determined. In cleft endemic areas in developing countries such as Ghana, early sonography investigation of foetus should also take into consideration unilateral CL deformity, especially in male foetus so as to educate and counsel involved parents how to feed and care for the unborn baby before surgical repair of the cleft.

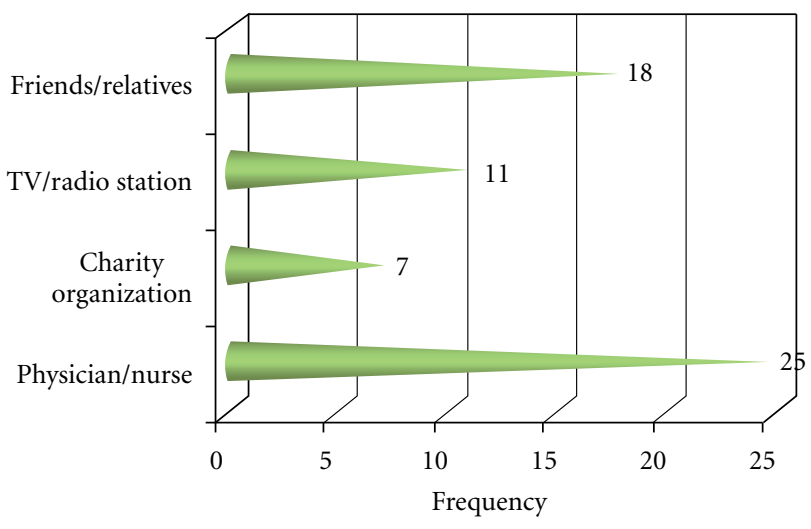

FIGURE 6: Media through which patients/parents heard about the Cleft Outreach Program.

Aziz et al. (2009) and Schwarz and Khadka (2004) reported in their studies that late presentation of patients with cleft deformities in developing countries is still very common $[5,6]$. Unfortunately in developing countries untreated $\mathrm{CL} / \mathrm{CPs}$ are found with increasing frequency, and patients often present to the surgeon far past the optimal time for closure of the cleft deformities [13, 17]. This study was not different from the already reported ones in terms of late presentation of patients with cleft deformities. Even as old as 21 years and above patients constituting $29.5 \%$ $(n=17)$ of the patients had their cleft deformities repaired. Due to the constant reporting of such situation in many orofacial cleft studies, an essential objective of this study was to determine reasons attributing to such occurrences in developing countries such as Ghana. The results of the study reveal that, lack of finance (money), unawareness of treatment availability, and superstition (the belief that it is a spiritual affair) were the three major reasons given by patients and/or parents. Lack of money being the commonest reason is not unexpected because Ghana is a developing country, 
TABLE 4: A summary of logical regression analysis of demographic and cleft features.

\begin{tabular}{lccccc}
\hline & Unilateral CL & Bilateral CL & Unilateral CP & Unilateral CL/CP & Bilateral CL/CP \\
\hline Age & 0.600 & 0.087 & 0.500 & 2.023 & 0.335 \\
Male & $0.017^{*}$ (right) & 0.801 & 1.900 & 0.099 & 0.294 \\
Female & 1.510 & 0.777 & 0.980 & 0.056 & 1.400 \\
\hline
\end{tabular}

"Donates significant value $(P<0.05)$.

where the majority of its citizens live on less than one US dollar a day; and on average US\$600 is required for cleft lip surgery. Notwithstanding this, all patients in the study were treated for free on the provisions of the National Health Insurance Scheme (NHIS).

The problem of lack of finances as a reason for late presentation of medical problems is certainly endemic throughout developing countries [6]. The problem is compounded for rural people, as they must pay for travelling and accommodation expenses in addition to the medical services at the health care center, where such surgery can be provided [6]. Adeyemo et al., in a similar study in Nigeria, reported lack of money (56.7\%), distance to health facilities (18.4\%), and a lack of knowledge of the availability of surgical repair services $(13.3 \%)$ as the three most common reasons for late presentations of CL/CP for repair [18]. Schwarz and Khadka [6] reported that the main reasons for late presentations of $\mathrm{CL} / \mathrm{CP}$ in Nepal were lack of knowledge of availability of services (31\%), lack of services near at hand (29\%), lack of finance $(24 \%)$, and lack of time (13\%). The former had a similar most common reason as this study, while the latter had lack of finance as the third factor. The difference in most common reason may be due to differences in geographical location, since, Ghana, Nigeria, and Nepal are all developing countries.

Free outreach cleft repair programs in Ghana and other developing countries will go a long way to alleviate the late presentations of CL/CP. This approach would also lessen much of the financial burden and time constraints associated with travelling to a regional center by bringing the health care closer to home. To solve the problem of lack of knowledge of the availability of surgical repair services in Ghana, increased access to primary health care services combined with providing primary health care workers with information regarding the availability of $\mathrm{CL} / \mathrm{CP}$ surgery would also reduce the rate of late presentation. This approach had been confirmed by the study as the appropriate procedure to disseminate information to patients and/or their relatives. Most (41.0\%) of the patients/relatives claimed to have had information about the outreach program via the health care worker (physician/nurse). Radio advertising and the involvement of charity organizations in community outreach program are also suitable means of informing communities of the availability of orofacial cleft management.

Several challenges are encountered in the management of patients with delayed presentation of cleft lip and palate especially in adulthood and adolescence. These include surgical, orthodontic, speech, anesthetic, and psychological challenges. Although sound knowledge of the fundamentals of cleft surgery will certainly allow any surgeon to repair an adult cleft lip or palate adequately, obtaining the most favorable surgical outcome may require creative modification to the design of the cleft secondary to various factors, including the increased size of the adult cleft [19]. Surgeons should be prepared to repair adult patients with cleft that are significantly enlarged in three dimensions. Closure will require significant soft-tissue dissection, as well as the possible use of biomaterials to repair wide palatal clefts [20].

\section{Conclusion}

Unilateral cleft lip constitutes most of the orofacial clefts in this study, with lack of finance been the commonest reason why patients delay in the repair of their deformity. The promotion of health education on orofacial cleft in our various health institutions, especially in endemic areas, and fully funded, well organized outreach programs, will go a long way to curve down the number of unrepaired clefts and reduce stigmatization in Ghana and other developing countries with similar conditions.

\section{Acknowledgments}

The authors are grateful to the nursing staff of the Global Evangelical Mission Hospital, Apromase-Ashanti and the South Tongu District Hospital, Sogakope, especially Nurses Antoinette Numado, Abiba Iddi, Ellen Alayon, Lucy Asilevi and Seyram Akpade for the accurate documentation of patients' data and also more especially for helping to manage these patients.

\section{References}

[1] M. A. Rawashdeh and B. Jawdat Abu-Hawas, "Congenital associated malformations in a sample of jordanian patients with cleft lip and palate," Journal of Oral and Maxillofacial Surgery, vol. 66, no. 10, pp. 2035-2041, 2008.

[2] A. T. Adenekan, A. F. Faponle, and F. O. Oginni, "Perioperative adverse airway events in cleft lip and palate repair," Southern African Journal of Anaesthesia and Analgesia, vol. 17, no. 6, pp. 370-373, 2011.

[3] A. Gritli-Linde, "The etiopathogenesis of cleft lip and cleft palate. usefulness and caveats of mouse models," Current Topics in Developmental Biology, vol. 84, pp. 37-138, 2008.

[4] J. C. Murray, "Gene/environment causes of cleft lip and/or palate," Clinical Genetics, vol. 61, no. 4, pp. 248-256, 2002.

[5] S. R. Aziz, S. T. Rhee, and I. Redai, "Cleft surgery in rural Bangladesh: reflections and experiences," Journal of Oral and Maxillofacial Surgery, vol. 67, no. 8, pp. 1581-1588, 2009. 
[6] R. Schwarz and S. B. Khadka, "Reasons for late presentation of cleft deformity in Nepal," Cleft Palate-Craniofacial Journal, vol. 41, no. 2, pp. 199-201, 2004.

[7] D. A. Sell and P. Grunwell, "Speech results following late palatal surgery in previously unoperated Sri Lankan adolescents with cleft palate," Cleft Palate Journal, vol. 27, no. 2, pp. 162-168, 1990.

[8] D. LaRossa, "Cleft palate," in Mastery of Plastic and Reconstructive Surgery, M. Cohen, Ed., p. 595, Little, Brown and Co., Boston, Mass, USA, 1994.

[9] F. Ortiz Monasterio, A. Olmedo, and I. Trigos, "Final results from the delayed treatment of patients with clefts of the lip and palate," Scandinavian Journal of Plastic and Reconstructive Surgery, vol. 8, no. 1-2, pp. 109-115, 1974.

[10] D. Pelchat, J. Bisson, N. Ricard, M. Perreault, and J. M. Bouchard, "Longitudinal effects of an early family intervention programme on the adaptation of parents of children with a disability," International Journal of Nursing Studies, vol. 36, no. 6, pp. 465-477, 1999.

[11] J. F. Simonds and R. E. Heimburger, "Psychiatric evaluation of youth with cleft lip-palate matched with a control group," Cleft Palate Journal, vol. 15, no. 3, pp. 193-201, 1978.

[12] P. Agbenorku, M. Agbenorku, A. Iddi et al., "A study of cleft lip/palate in a community in the South East of Ghana," European Journal of Plastic Surgery, pp. 1-6, 2010.

[13] P. Donkor, D. O. Bankas, P. Agbenorku, G. Plange-Rhule, and S. K. Ansah, "Cleft lip and palate surgery in Kumasi, Ghana: 2001-2005," Journal of Craniofacial Surgery, vol. 18, no. 6, pp. 1376-1379, 2007.

[14] P. Agbenorku, S. Ansah, A. Acheampong et al., "Komfo Anokye Teaching Hospital multidisciplinary cleft clinic," Journal of Craniofacial Surgery, vol. 22, no. 2, pp. 532-536, 2011.

[15] D. F. Wyszynski, T. H. Beaty, and N. E. Maestri, "Genetics of nonsyndromic oral clefts revisited," Cleft Palate-Craniofacial Journal, vol. 33, no. 5, pp. 406-417, 1996.

[16] J. Wilson and A. Hodges, "Cleft lip and palate surgery carried out by one team in uganda: where have all the palates gone?" The Cleft Palate-Craniofacial Journal, vol. 49, no. 3, pp. 299-304, 2012.

[17] A. L. Nwoku, "Experience on repair of unoperated cleft patients," Nigerian Medical Journal, vol. 6, pp. 417-421, 1974.

[18] W. L. Adeyemo, M. O. Ogunlewe, I. Desalu et al., "Cleft deformities in adults and children aged over six years in Nigeria: reasons for late presentation and management challenges," Clinical, Cosmetic and Investigational Dentistry, vol. 2009, no. 1, pp. 63-69, 2009.

[19] I. T. Jackson, A. A. Moreira-Gonzalez, A. Rogers, and B. J. Beal, "The buccal fat pad-a useful technique in cleft palate repair? " Cleft Palate-Craniofacial Journal, vol. 41, no. 2, pp. 144-151, 2004.

[20] W. L. Adeyemo, A. L. Ladeinde, M. O. Ogunlewe, and B. O. Bamgbose, "The use of buccal fat pad in oral reconstruction-a review," The Nigerian postgraduate medical journal, vol. 11, no. 3, pp. 207-211, 2004. 


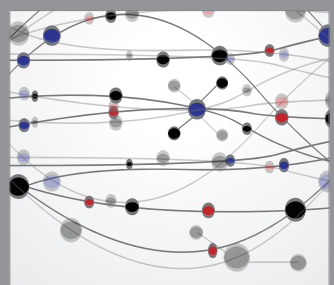

The Scientific World Journal
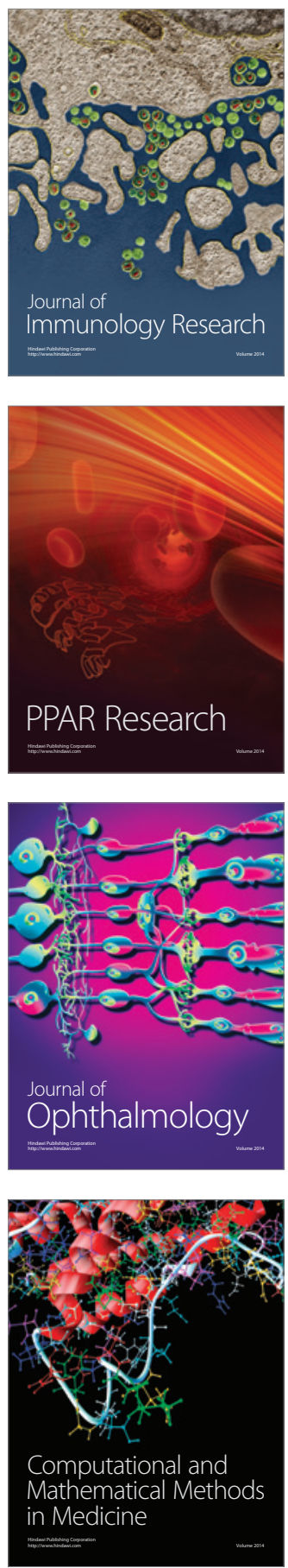

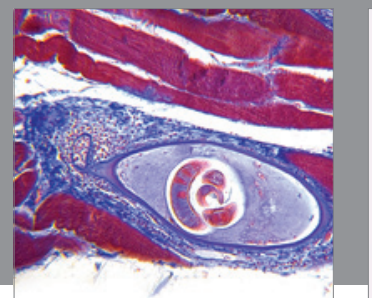

Gastroenterology

Research and Practice
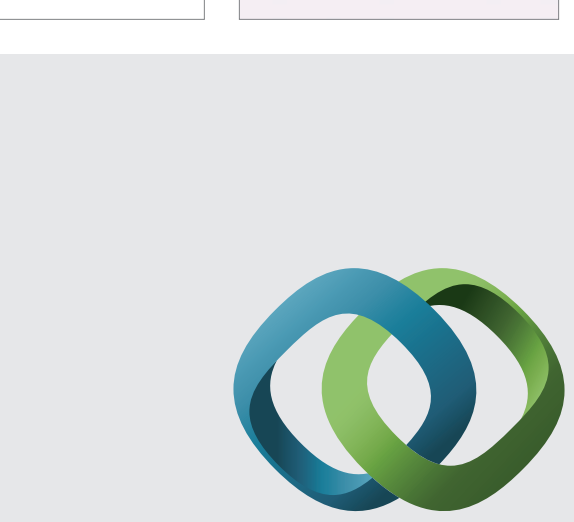

\section{Hindawi}

Submit your manuscripts at

http://www.hindawi.com
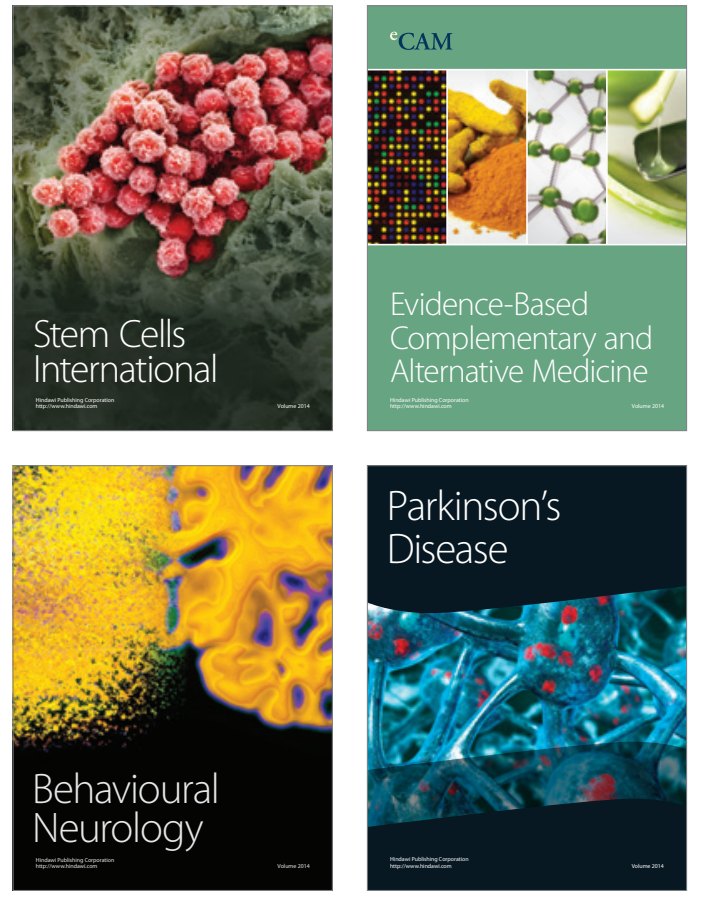
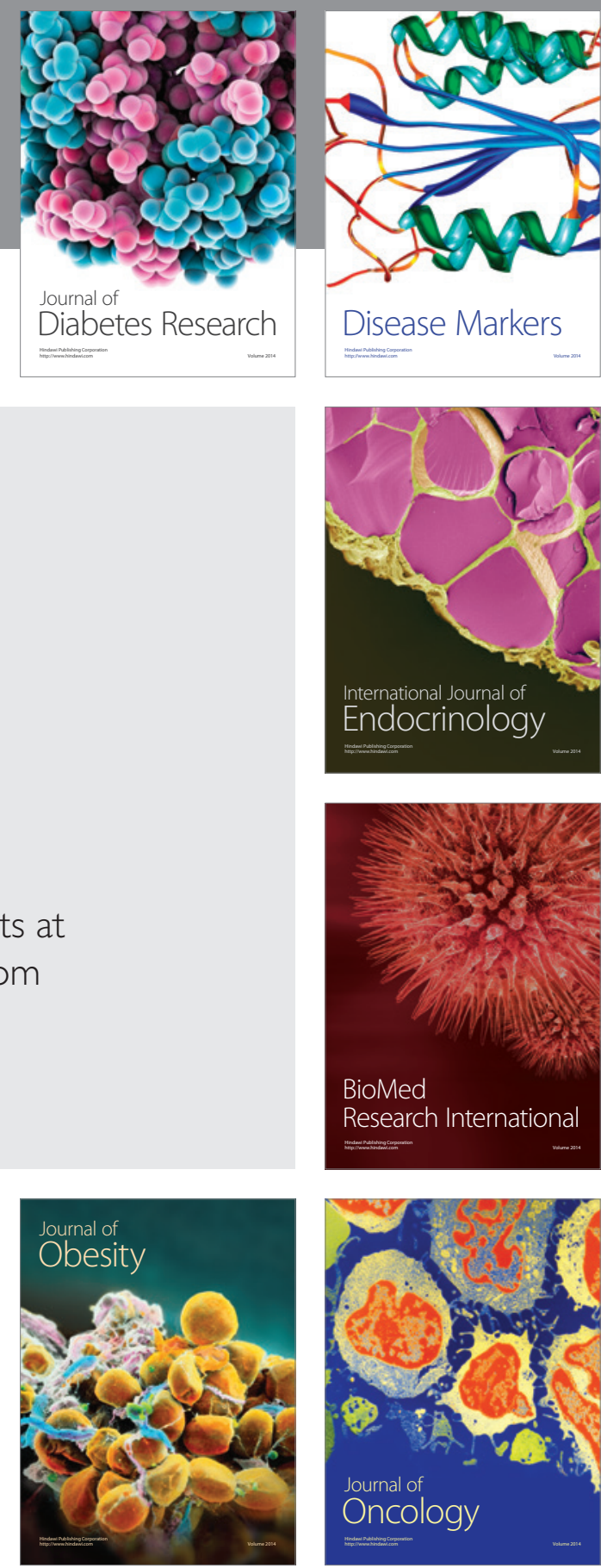

Disease Markers
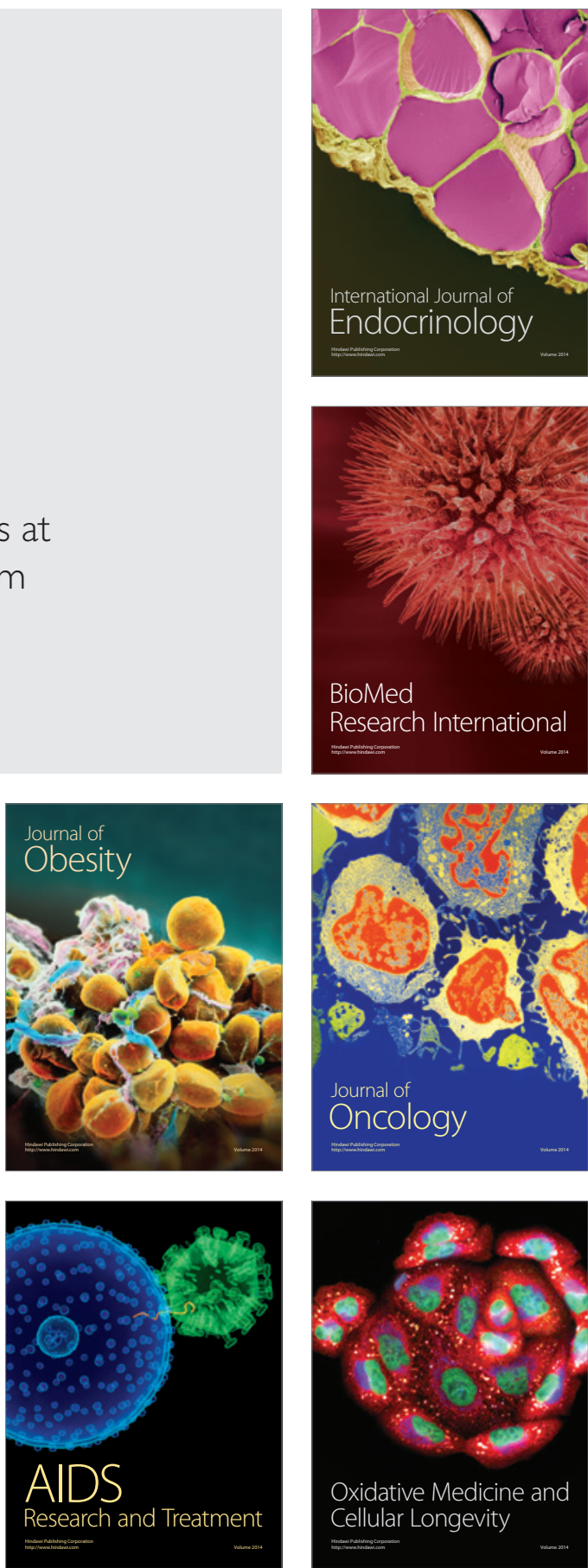